\title{
The Dangers of Sport on an Operational Deployment
}

\author{
JC Clasper
}

\begin{abstract}
This study, a retrospective review of the orthopaedic outpatient work from a multinational hospital in Bosnia, further confirms the dangers of sport on an operational tour. Sports injuries were shown to be a major cause of morbidity, affecting both the operational effectiveness of the force and also resulting in a number of careerthreatening injuries. In particular, football was shown to be the most common cause of injury and the wisdom of allowing this sport during operational tours must be questioned.
\end{abstract}

\section{Introduction}

A number of authors have reported the epidemiology of disease and non-battle injuries during operational tours $(1,2,3)$. Orthopaedic conditions, particularly musculoskeletal injuries are amongst the commonest reasons for both inpatient and outpatient visits, and injuries from sport have been shown to be a common cause of such conditions.

The morbidity of sport related injuries has been documented in civilian practice (4), and epidemiological data on sport injuries during the operational deployment of British troops in Bosnia, has also been reported. Adams et al (5) demonstrated the adverse effect of sport, particularly football, and recommended that commanders are made aware of the high injury rate.

Much of the previous work has been carried out at the primary care level, and the aim of this study was to investigate the incidence and consequences of sports injuries presenting to an orthopaedic surgeon, during an operational tour in Bosnia-Herzegovina.

\section{Methods}

A retrospective review of the casenotes of $\frac{5}{\pi} 1$ patients presenting to the multination integrated medical unit at Sipovo in BosnfaHerzegovina during the period 1 June $20 \overrightarrow{\mathscr{O}}$ to 30 November 2000 was carried ot During this 6 month period, 203 ne 9 . patients presented to the orthopaed surgeon; these patients form the basis of thas study. During this period the Canadians, Dutch and British provided the orthopaedict surgeon in rotation.

The 203 casenotes were reviewed in detiol and the presenting complaints were dividesd into acute or chronic, depending on the presence of symptoms prior to the deployment. The relationship to sport $\overrightarrow{\text { ga }}$ both categories was determined and the outcome for all sporting injuries we्6 determined.

The hospital provided the role 3 medical care for the approximately 4700 troops of to Multinational Division Southwest. T/ge majority of these troops were British wige significant contributions from the Canadians, Dutch and Czech Republic.

\section{Results}

Of the 203 patients, $54(26.6 \%)$ presented with chronic problems, but of these 18 (33.3\%) had been exacerbated by sportia activities during the tour. The remaining 1 , $(73.4 \%)$ presented with acute problems, arad of these sports injury was the most common cause. Traffic accidents, military traini凫

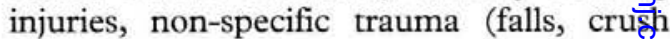
injures etc) and acute orthopaedic problerg s such as sciatica accounted for the remaindgr of the causes. These data are presented in Table 1.

Football was again the most comm cause of injury accounting for $34.4 \%$ of a्Pl sporting injuries, and the lower lim
Lt Col J C Clasper DPhil FRCSEd(Orth) RAMC

Consultant Orthopaedic Surgeon

MDHU Frimley Park

Hospital, Portsmouth Road, Frimley, Surrey, GU16 5UJ.

Table 1. Number and aetiology of orthopaedic outpatients

\begin{tabular}{|c|c|c|c|}
\hline \multirow{2}{*}{$\begin{array}{l}\text { Classification of Complaint and Aetiology } \\
\text { Trauma - Traffic accident }\end{array}$} & \multicolumn{2}{|c|}{ Number $(\%)$ of casualties $n=203$} & \multirow{2}{*}{$\stackrel{\check{C}}{\mathscr{C}}$} \\
\hline & 13 & $(6.4)$ & \\
\hline - Sporting injury & 61 & $(30)$ & $\overline{\mathrm{O}}$ \\
\hline - Military training & 7 & $(3.4)$ & $\frac{2}{1}$ \\
\hline - Non-specific trauma & 52 & $(25.6)$ & \\
\hline - Cause not recorded & 11 & $(5.4)$ & 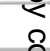 \\
\hline Acute non-traumatic orthopaedic problems & 5 & $(2.5)$ & 它 \\
\hline Chronic - exacerbated by sport & 18 & $(8.9)$ & $\stackrel{\text { Qิ }}{\mathrm{J}}$ \\
\hline - not related to sport & 36 & $(17.7)$ & \\
\hline
\end{tabular}




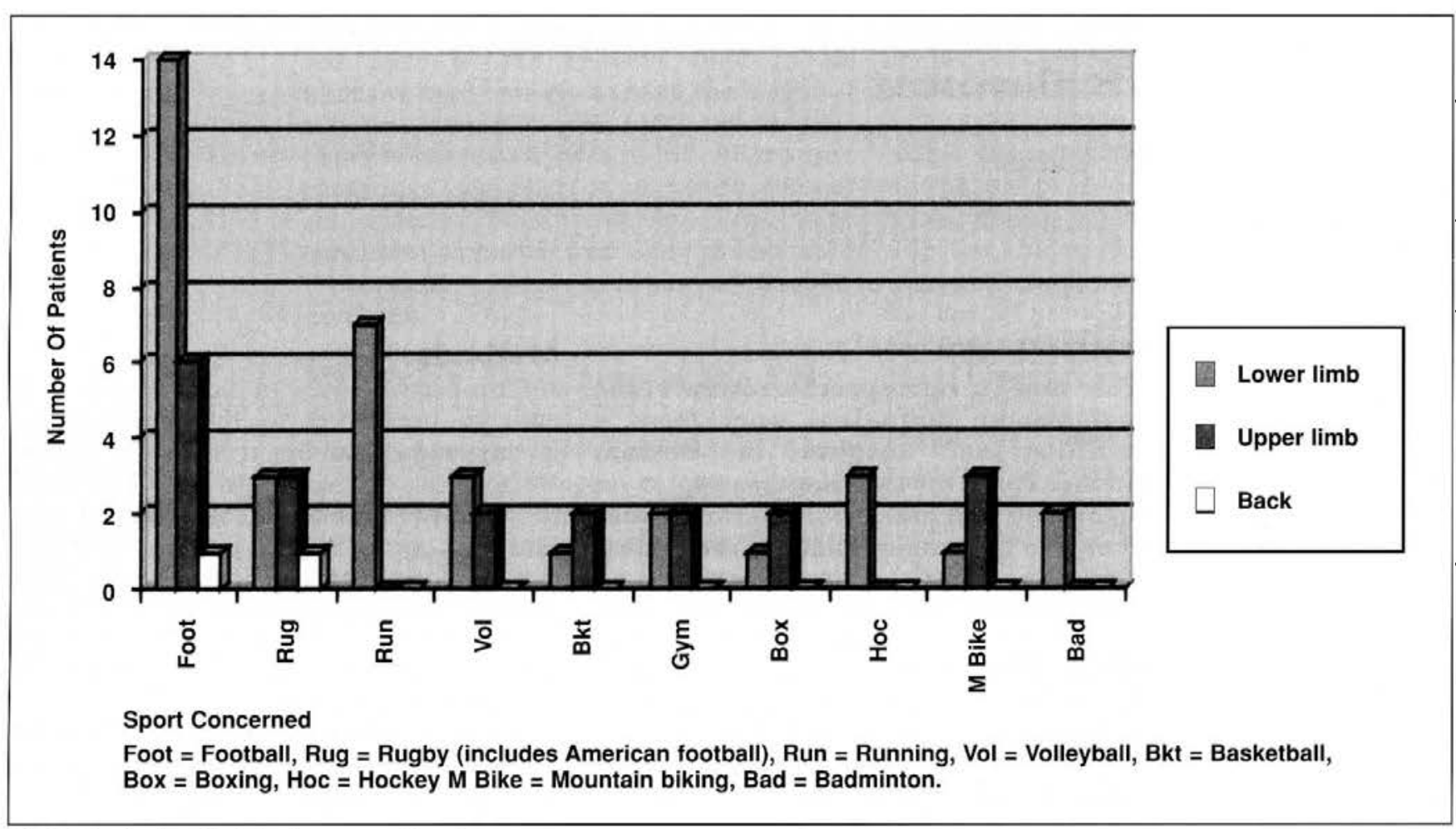

Fig 1. Distribution of injuries by sport and location.

particularly the ankle, was the most common site of injury. These data are presented in Figure 1. For simplicity the 2 American football injuries ( 1 ankle, 1 hand) are included with rugby injuries. All weighttraining, multigym and rowing, cycling and running trainers are grouped together as gym injuries. In addition, boxing injuries includes boxing training as well as competitive events. One patient sustained a hand injury due to sport, but the specific sport was not recorded.

Only $5(8.2 \%)$ of the patients presenting with sports injuries were discharged straight back to full duties. The majority $(70.5 \%)$ received light duties (mean 14.4 days), but 13 patients $(21.3 \%)$ required admission to hospital of whom 9 were subsequently evacuated out of theatre.

Several patients were evacuated for further investigation with significant, careerthreatening, knee injuries and in addition 13 significant injuries were diagnosed at the multinational hospital. These injuries and the sports responsible are shown in table 2 .

Table 2. Significant injuries and the sports responsible

\begin{tabular}{|l|l|}
\hline Injury & Sport responsible \\
\hline Achilles tendon rupture $\times 2$ & Badminton \\
\hline Ankle - fracture dislocation & Football \\
\hline Ankle - fracture $\times 2$ & American football, Gym \\
\hline Patella dislocation & Boxing \\
\hline Thumb fracture $\times 2$ & Football, Rugby \\
\hline Finger - fracture dislocation $\times 2$ & Football, Basketball \\
\hline Scaphoid fracture & Basketball \\
\hline Wrist fracture & Football \\
\hline Shoulder dislocation & Boxing \\
\hline
\end{tabular}

\section{Discussion}

This paper should not be seen as an attempt $\tilde{O}$ to discourage sport on an operational tour. Within the armed forces sport is necessary to maintain fitness, encourage team spirit, and prevent boredom particularly on an operational tour. However, sports injuries $\stackrel{2}{0}$ have always been a concern for the British armed forces, and all commanders and $\overrightarrow{\overrightarrow{0}}$ medical personnel have a duty to prevent avoidable injuries and reduce the level of injury to an absolute minimum. Service personnel are a risk group as young adults have been shown to have the highest rate of sports injuries (6). This was also demonstrated by Garraway and Macleod (7) in a review of rugby injuries which reported that the highest injury rate occurred in the 20-24 year old age group. In their prospective study the authors noted that an injury occurred, on average, every 1.8 games.

The incidence of sports injuries in British servicemen has been investigated and a mean sports injury rate of 6.5 per 1000 personnel per year was reported during the period $1969-80$ (8). Football and rugby were found to be the commonest causes of injury. Given an estimated strength of 4700 for the multinational division, then this study documents a far higher rate of 26 sports ? injuries per 1000 personnel per year. Again, football was the most common cause of injury. Although these figures relate to spring summer and autumn, when increased sporting activities could be expected, this study documents only those patients that $\frac{8}{8}$ presented to the force orthopaedic surgeon. It is likely, therefore, that this represents only a small proportion of the sports injuries and 
this has been confirmed by Adams et al (5). In their report, also from former Yugoslavia, the authors documented that, during the month of April 1996, 3\% of the practice population of 1428 presented to the primary care centre with a sports injury. This equates to an annual incidence of 370 per 1000 personnel per year. Owen and Macmillan (10), in a pilot study of the J95 morbidity reporting system in Bosnia, have also noted that sports injuries were a significant cause of morbidity and were responsible for $10 \%$ of the aeromedical evacuations out of theatre. At these levels of injury the operational effectiveness of a unit must be compromised.

This very high rate of sports injuries is related to a number of factors present on an operational tour, particularly when there is a low risk of military injuries. Once the initial deployment phase has been completed troops separated from their families have a lot of spare time. In an effort to prevent boredom and maintain fitness levels when facilities are limited, sport is encouraged. Often, as reported by Adams et al (5), the games are ad hoc, without appropriate equipment, training or facilities. This is particularly true for contact or team sports and often personnel with little previous experience of the sport will participate. It is probable that non-sportsmen would be more likely to play football than rugby and this may be the reason for the high incidence of football injuries. In this study it was impossible to differentiate properly organised and supervised matches by experienced players from impromptu games for allcomers. The findings of Croft et al (2) are demonstrated by the 3 hockey injuries reported in this study, in Canadian soldiers playing an ad hoc version of 'street' hockey without the proper equipment.

Due to difficulties obtaining the exact number of personnel in theatre, particularly non-British troops, the injury rate has not been broken down by nation. However, the British troops appeared to have the highest injury rate and the Czechs the lowest. This, however, may reflect differing criteria for referral to an orthopaedic surgeon rather than different injury rate. In addition, the different nations participate in different sports (e.g. street hockey) and, therefore, injury rates would be expected to differ.

In this study it is not possible to relate the number of injuries to the time spent playing specific sports and, therefore, the rate of injury cannot be calculated. This is the major weakness of this study, but on an operational tour, where most sport is not planned, accurate figures would never be possible. This makes meaningful comparison with civilian reports, or even military sports injury rates during non-operational deployments impossible. It is likely, however, that the rates reported in this study are higher than civilian or non-operational work due to the ad hoc nature of sport in Bosnia, and the apparent $\bar{c}$ increased frequency of sporting activity? amongst un-accompanied personnel, when little social life is available.

Civilian reports have demonstrated that $\stackrel{\vec{\Phi}}{\stackrel{2}{\overparen{D}}}$ contact sports, particularly football have $a \circ$ high rate of injury. De Loës et al (9) reported that football had the 3 rd highest rate after ice hockey and handball. Sports normally considered high risk such as skiing or horse를 riding had a far lower injury rate. Running $\frac{\overline{\bar{C}}}{\bar{\circ}}$ and physical training were shown to have low $\frac{\overrightarrow{0}}{0}$ rates of injury and it would seem prudent to $\frac{2}{0}$ recommend these sports on an operational ${ }^{\circ}$ tour. However, the wisdom of encouraging $\overrightarrow{0}$ football on an operational tour, particularly $\overrightarrow{\vec{H}}$ for essential personnel must be questioned. $\stackrel{\omega}{\omega}$ According to Adams et al (5), one German unit banned this sport on an operational tour because of the high injury rate. Given the high injury rate then this should be considered for certain key personnel.

There is certainly a requirement to $\dot{\infty}$

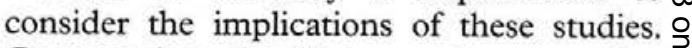
Commanders should be made aware that sport is a significant cause of morbidity and $\bigcirc$ it would seem prudent to consider a $\stackrel{0}{\circ}$ prospective study, looking particularly at the $\stackrel{\mathbb{\Phi}}{\stackrel{\Phi}{ }}$ incidence of injury per unit of time $\tilde{\sigma}$ participated in a sport, and the relationship of injuries in organised, supervised events compared to ad hoc events. This may lead to ways of reducing the injuries, particularly $\frac{\partial}{0}$ career-threatening injuries. In preparation for an operational deployment troops are given presentations on mine awareness, medical $\overrightarrow{\vec{D}}$ issues including genitourinary problems, as well as other local hazards. This includes driving, as traffic accidents are often the leading cause of death on such tours. Sports injuries are not discussed, despite the fact that soldiers are more likely to be injured during sport than any other activity including traffic accidents. A presentation on sports injuries should be considered during the predeployment training.

\section{References}

1. Kortepeter M G, Ljaamo S K. Disease and nonbattle injury among United States soldiers deployed in Bosnia-Herzegovina during 1997: Summary primary care statistics for Operation Joint Guard. Mil Med 1998;163:733-742.

2. Croft A M J, Hoad N A and Dale R F, Hospitalisation of British troops during Operation Joint Endeavor (Bosnia). Mil Med 1999;164:460465.

3. Writer JV, DeFraites R F and Keep LW. Non-battle injury casualties during the Persian Gulf War and other deployments. Am F Prev Med 2000;18:64-70.

4. de Loës M, Goldie I. Incidence rate of injurie during sport activity and physical exercise in a rura Swedish municipality: Incidence rates in 17 sports Int $\mathcal{f}$ Sports Med 1988;9:461-467.

5. Adams M S, Croft A M J. Sports injuries in British troops deployed on Operation Resolute (Bosnia). $\mathcal{F}$ R Army Med Corps 1997;143:35-38

6. Kujala U M, Taimela S, Antti-Poika I, Orava S, Tuominem R, Myllynen P. Acute injuries in soccer, ice hockey, volleyball, basketball, judo, and karate: analysis of national registry data. $B M \mathcal{F}$ 
1995;311:1465-1468.

7. Garraway M, Macleod D. Epidemiology of rugby football injuries. Lancet 1995;345:1485-1487.

8. Tointon J A. Sports injuries in the services 19691980. F R Army Med Corps 1984;130:193-197.

9. de Loës M. Medical treatment and costs of sport- related injuries in a total population. Int $f$ Spor $\stackrel{C}{\zeta}$ Med 1990;11:66-72.

10. Owen J P, Macmillan A H M. A pilot study of J9 in secondary care in Bosnia. I R Army Med Cors 1998;144:79-84.

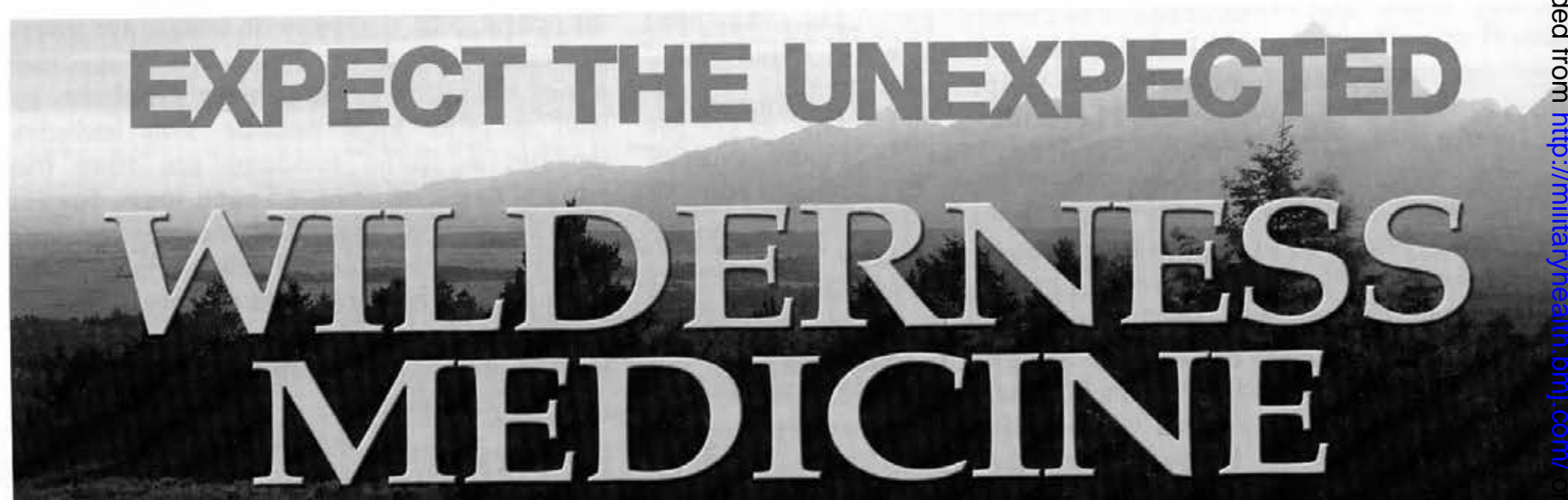

FOURTH EDITION

PAUL S. AUERBACH, MD, MS, FACEP

Clinical Professor of Surgery, Division of Emergency Medicine, Stanford University School of Medicine, Stanford, CA, USA

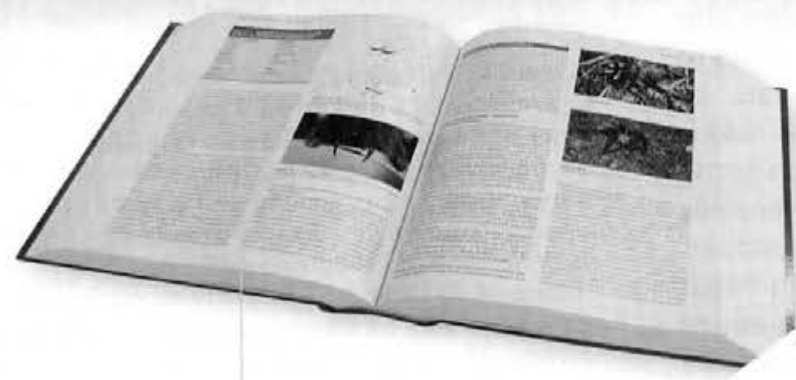

Diagrams and tables provide stepby-step and at-a-glance instructions for treatment
- Includes more than 1400 illustrations

- Strong emphasis on injury prevention

- Discusses diagnosis as well as treatment

- Advice on how best to use available materials

- Well organised for quick reference

- Covers even the most unexpected situations

- Heavily revised - much new material added

March 2001 • 0323009506 • Mosby • Hardback • $1800 \mathrm{pp} \cdot 1400$ illus 